\title{
Methodology of formation of multi-layered coatings for carbide cutting tools
}

\author{
Sergey N. Grigoriev and Alexey A. Vereshchaka ${ }^{a}$ \\ Moscow State Technological University "STANKIN", Vadkovsky per. 1, Moscow 127994, Russia
}

Received 16 September 2016, Accepted 8 November 2016

\begin{abstract}
In this paper, we consider the development of the methodology for the formation of nanostructured multi-layered composite coatings to improve the cutting properties of carbide cutting tools in the high-performance machining of various materials. The methodology for the formation of the composition, structure, and properties of developed composite coatings with a three-layered architecture was based on the phenomenological theory of the thermodynamic criteria for the evaluation of adhesion, and the assumption of the prevailing adhesion-fatigue wear of carbide cutting tools. The synthesis of coatings was carried out through filtered cathodic vacuum-arc deposition. The hardness, adhesion, and cutting properties of the developed coatings deposited on the carbide substrates were studied. It was found that the synthesized coatings had a nanoscale grain structure and thickness of sublayers, which significantly increased the area of intergranular and interlayer boundaries and provided a considerably balanced relation of the most important characteristics of the coating, such as "hardness-heat resistance". Such structures are characterized by increased toughness and resistance to the formation and development of "brittle" cracks and more efficient resistance to fractures in conditions of complex stress from external influences. It is revealed that, in the longitudinal turning of steel, carbide tools with the developed coatings demonstrated a tool life of five times higher than the tool life of uncoated tools and up to three times higher than the tool life of tools with standard coatings.
\end{abstract}

Key words: Multi-layered coatings / vacuum-arc processing / tool life of coated carbide tools

\section{Introduction}

At present, carbides are the main materials for the manufacture of tools used in various technological machining operations for cutting. The performance properties of carbide tools are based on the development of innovative brands with fine and superfine structures and carbides with bindings of increased heat resistance; for example, those with cobalt-rhenium bindings are improved significantly. Carbide tools with wear-resistant coatings of modern generation are increasingly used, and at present, their portion in manufacturing reaches $85-90 \%$ [1]. Mechanical engineering productions are increasingly using high-performance cutting tools of carbides with complex composite wear-resistant coatings, the use of which contributes to the solution of several of the most important industrial technological challenges associated with the growth of productivity, the increase in accuracy, and the quality of machining parameters. Furthermore, it contributes to the reduced consumption of expensive tool materials, such as carbides, and decreases the nega-

${ }^{a}$ Corresponding author: ecotech@rambler.ru tive anthropogenic effect on the environment since highperformance carbide tools allow the machining processes to be conducted without the use of coolant fluids for cutting $[1-10]$.

It should be noted that, despite significant progress in the production of high-quality coated carbide tools, cutting tools remain the weakest link in technological cutting systems, which constrains the significant increase in their efficiency. To the highest degree, all the above refers to the intermittent cutting processes [14], heavy roughing [10], and cutting of hard-to-cut materials [2-4].

The analysis of the properties of nitride, carbide, and boride compounds is based on the refractory transition metals of Groups IV-VI of the periodic table. Those most suitable for use as wear-resistant coatings for cutting tools have been shown in the following $[1-4,6,7,9]$. Based on the fundamental principles of thermodynamics, the tribological laws of contact processes in cutting, and the conceptual idea of the dual nature of a coating as an intermediate technological environment between the tool material and the machined material, it is possible to formulate general requirements for coatings for cutting tools $[6,9,11,13]$. 
These requirements for coatings include, on one hand, the need to reduce the thermomechanical effect on contact areas of a tool to reduce tool wear rate in cutting and, on the other hand, the need to ensure high coating adhesion strength with respect to the tool material.

It should be noted that mono-layered coatings (for example, titanium nitride ( $\mathrm{TiN}$ ) or titanium aluminum nitride (TiAlN)) do not meet the dual nature and the basic requirements for coatings since they are unable to simultaneously provide a reduction in contact loads and high adhesion strength to the tool material. In this regard, the practice of manufacturing coated tools increasingly uses nanostructured multi-layered composite coatings (NMCCs) with variable chemical composition and properties to meet the phenomenological requirements for coatings $[1,2,2,3,6,8-13]$.

In this paper, we consider the challenges aimed at the development of the generalizing methodology of the formation of multi-layered composite coatings for cutting tools.

\section{Theoretical prerequisites}

One of the most important tasks in the development of cutting tools with a wear-resistant coating is the clarification of the basic requirements for the coatings, based on the conditions of the maximum duration of the operation without failure, the role in the complex processes of tool wear, and the interaction with the tool material in cutting conditions.

In the machining of structural steels with the usual cutting modes for production conditions, the maximum contact stresses for a fresh cutting tool may fluctuate within 400-800 $\mathrm{MPa}$ and, in extreme conditions, can reach 3000-4000 $\mathrm{MPa}$. In the same conditions, cutting tools are exposed to high temperatures of up to 200$1100{ }^{\circ} \mathrm{C}$. It should be noted that, in discontinuous cutting, in the formation of chips of a discrete type and in the variation of allowance, the tool contact areas are exposed to intense influence of alternating stresses, and the thermal influence on the tool is of cyclic character.

The immediate causes of tool wear in the contact areas are the integral processes of abrasive, adhesive, adhesive-fatigue, corrosion-oxidation, and diffusion wear. If resistance to abrasive wear can be effectively improved through the increase in hardness of the contact areas, then adhesion-fatigue and diffusion types of tool wear largely depend on the crystal-chemical structures of the tool material and machined material.

In expressed adhesive types of tool wear, which usually occur in cutting at low and medium speeds (at temperatures of $350-550{ }^{\circ} \mathrm{C}$ ), the finest particles of the tool material are torn off or cut off by adhesion forces. The wear rate and intensity of the appearance of adhesion "bridges" are very high. In one meter of cutting, each point of contact is subjected to a thousand-fold effect of cutting stresses [6]. Such an effect results in fatigue of local volumes of tool material and their subsequent failure. In these conditions, the role of the coating should be the reduction of the intensity of the seizure of the tool contact areas with the material being processed, and the coating itself should be sufficiently effective to resist fatigue failure. The rate of adhesion wear of a tool with a coating may be reduced due to a sharp increase in the relation $H V_{C / T M} / H V_{M M}$ as compared with the relation $H V_{T M} / H V_{M M}$, where $H V_{C / T M}$ is the hardness of the composition of the coating-tool material and $H V_{T M}$ and $H V_{M M}$ are the hardness of the tool material and the machined material, respectively. As the cutting speed increases, the temperature in the machining zone exceeds $600-700{ }^{\circ} \mathrm{C}$, and the interdiffusion processes are activate, resulting in mutual diffusion dissolution of components of the tool material and the machined material. Interdiffusion results in structural transformations occurring in the local surface layers of the tool material, which in turn results in their embrittlement and softening. At the same time, stresses in the shear plane increase as a result of the hardening of the volumes of the machined material and that results in the destruction of the softened structures of the tool material.

Sections of elastic (discrete) contact between the contact surfaces of the tool material and the machined material are exposed to the influence of the active reagents of the environment $\left(\mathrm{O}_{2}, \mathrm{~N}_{2}, \mathrm{CO}, \mathrm{CO}_{2}\right.$, etc.). This results in an intensive oxidation and corrosion of the tool areas in the elastic contact. In these conditions, the role of the coating is to improve the resistance of the tool material to high-temperature corrosion and oxidation.

After the analysis of the above, it is possible to summarize the basic requirements for the coatings for the cutting tools, which should meet the following requirements:

- Coatings should be able to resist fracture at pressures reaching $4000 \mathrm{MPa}$;

- Coatings should maintain their properties at temperatures of $200-1100{ }^{\circ} \mathrm{C}$;

- When the temperature rises, various figures of physical-mechanical and thermophysical properties of the tool and coating materials (such as the elasticity modulus, Poisson's constant, coefficient of linear expansion, hardness, etc.) should not result in dangerous stresses at the boundaries of their section;

- Coatings should be characterized by sufficiently high fatigue strength, impact toughness, and low sensibility to influence the force and temperature loads of a cyclical nature;

- Coatings should be characterized by sufficient resistance to macro- and microfractures in the conditions of integral processes of abrasive, adhesive, adhesivefatigue, corrosion-oxidation, and diffusion wear;

- Coatings should be characterized by sufficiently high resistance to solid and liquid-phase diffusion reactions with the machined material;

- Coatings should increase the resistance of the tool material to high-temperature corrosion and oxidation.

The analysis of various options of interaction of the coating material and tool material described above can contribute to the conclusion that it is 


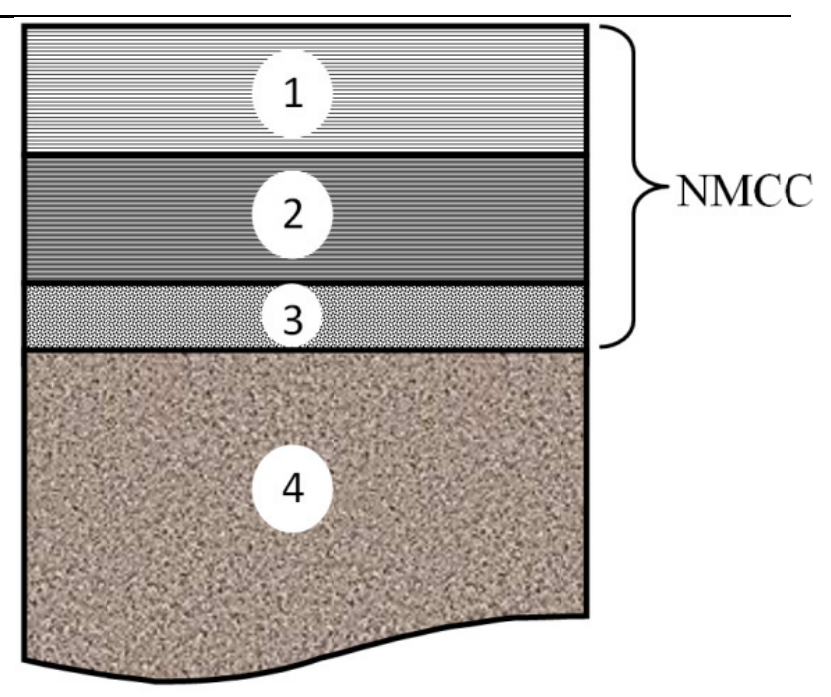

Fig. 1. Three-layered architecture of the NMCC for cutting tools: 1 - wear-resistant layer; 2 - intermediate layer; 3 - adhesive layer; 4 - tool material (substrate).

necessary to perform two conditions for the synthesis of coating:

- Active interaction of contacting phases provides strong adhesion between the coating material and the tool material;

- Lack of interaction between the tool material and coating material in the coating-synthesis process results in the preservation of the original physical and mechanical properties of the tool material and promotes efficient performance of the coating in operating the tool.

To comply simultaneously with both conditions of coating synthesis, it is necessary to ensure that the interaction of the coating material and the tool material occur only at the time of formation of the coatings at temperatures most effectively providing such interaction. In the subsequent operation of the tool with coating, this interaction should be slowed or completely stopped. This means that if the temperature of coating formation highly exceeds its operating temperature, then the tool with coating is highly efficient during operation.

The nature of the bond between the coating and the tool material has a great influence on the transformation of the tool material properties and consequently on the operational capabilities of the tool. In turn, the formation of the type of bond between the coating material and the tool material is largely dependent on the structural and kinetic conditions of the coating formation.

It should be noted that, according to a set of requirements and the dual nature of coatings, multi-layered composite coatings may comply with the requirements set forth. In this regard, we consider the concept of the coating referred to as the NMCC based on a three-layered architecture for cutting tools, in which each layer corresponds to a predetermined functional purpose (Fig. 1).
Based on the analysis of the functions of the NMCC as an intermediate technological environment between the tool material and the machined material, it is possible to formulate the functional requirements to its basic elements:

- Wear-resistant layer should be characterized by the highest possible physical and chemical passivity regarding the machined material, which is provided as the positive figure of the difference of the isobar potential $\Delta G_{T}^{0}$ of the reaction in the two-dimensional monoatomic boundary layer between them;

- Adhesive Layer 3 should be characterized by the highest possible crystal-chemical compatibility with the material of the substrate (cemented carbide), which provides strong adhesion with the substrate material at the negative figure of the difference of isobar potential $\Delta G_{T}^{0}$ of reaction in two-dimensional monoatomic boundary layer;

- Intermediate Layer 2 should be characterized by the highest possible crystal-chemical compatibility with wear-resistant (1) and adhesive (3) layers of the NMCC as the negative figure of the difference of the isobar potential $\Delta G_{T}^{0}$ of the reaction with the wearresistant and adhesive layers.

In addition to the need to ensure sufficient adhesion strength between Layers 1 and 3 of the coating, an intermediate Layer 2 can further perform the barrier functions of interdiffusion between the tool material and the machined material as well as the heat flows from the friction heat sources to the tool. Furthermore, it makes a significant contribution to improving the crack resistance and inhibition of the intensity of the cracking processes in the coating in general.

The improvement of the efficiency of the multi-layered coatings was achieved based on optimizing the parameters of the architecture and the directed choice of the physical and mechanical properties of the separate layers, depending on the characteristics of the technological process of cutting and the properties of the machined material.

For composite multi-layered coatings, it is extremely important to choose the composition and properties of the wear-resistant layer of the coating. To evaluate the composition of the wear-resistant Layer 1 of the NMCC, it is necessary to choose the wear mode of the cutting tool. Given the fact that adhesion-fatigue wear is the main mechanism of wear of carbide cutting tools with and without coatings, this wear mode was chosen as the main one in the development of the compositions and parameters of the NMCC layers [6]. In accordance with this approach, the minimization of the adhesion-fatigue wear of the tool is achieved at the minimum of weight lost by the tool material $M a \rightarrow \min$ :

$$
M a=K_{a} \cdot \rho \cdot F_{a}\left(J \cdot \sigma_{a} / \sigma_{p}\right),
$$

where $K_{a}$ is the coefficient of adhesion (volume), $\rho$ is the density of tool material, $F_{a}$ is the nominal contact area, $J$ is the intensity of bonding, $\sigma_{a}$ is the strength of bonds in the bonding nodes, and $\sigma_{p}$ is the resistance of the tool 
material to fracture. Meanwhile, the intensity of adhesion can be evaluated using the relation:

$$
J=\left(N_{T}+N_{M}\right) F_{a},
$$

where $F_{a}$ is the nominal contact area, and $N_{T}$ and $N_{M}$ are the number of active centers per unit of contact area at the thermal and the mechanical activation, respectively. The value of $N_{b f T}$ can be evaluated through the equation:

$$
N_{T}=v \cdot T \cdot e^{Q t / K \theta}
$$

where $v$ is the free frequency of valence atoms, $T$ is time, $Q_{T}$ is the energy of thermal activation, and $K$ is the Boltzmann constant, while $\theta$ is the absolute temperature. The value of $N_{M}$ can also be determined using the following relation:

$$
N_{M}=\rho_{1} . S . b,
$$

where $\rho_{1}$ is the density of dislocations, $S$ is the average length of the dislocation path, and $b$ is the Burgers vector. The speed of dislocation motion can be estimated from the equation:

$$
V_{D}=S \cdot \tau^{n},
$$

where $\tau$ is the stress, and $n$ is the exponent, depending on the hardness of the material. With the optimal composition of the outer layer of the multi-layered composite coating, it is possible to achieve compliance with the condition $M a \rightarrow$ min.

Equations (1)-(5) can be used for evaluation of the factors that have the greatest effect on the level of chemical-physical interaction (adhesion) of the wearresistant Layer 1 of the NMCC of the adhesion with the machined material and thus the intensity of the adhesionfatigue wear. Such factors include the cutting temperature, free frequency of valence atoms $v$, which correlates with the statistical weight of the atoms of the most stable electron configurations (SWASC) and hardness of the tool material (upper Layer 1 of the NMCC), which has a strong influence on the mobility (speed) of dislocations $V_{D}(5)$. The tendency to adhesion will increase under the following conditions:

- With the increase in temperature (up to the beginning of intense oxidation or thermal softening of adhesive bond bridges);

- With the increase in free frequency of valence atoms $v$, which correlates with the statistical weight of the atoms of the most stable electron configurations (SWASC);

- With the increase in the speed of mobility of dislocations $V_{D}$, which is inversely proportional to the hardness of the tool material or top Layer 1 of the NMCC.

In cases of problems in the use of the tabulated values of the components $N_{T}$ and $N_{M}$ (see Eqs. (3)-(4)), assumptions were made when determining them. The thermal component $N_{T}$ correlates with the melting point of the material of Layer 1 of the NMCC:

$$
N_{T}=C \cdot T^{\theta / \theta_{m}}
$$

where $C$ is a constant, $\Theta$ is the absolute temperature, and $\Theta_{m}$ is the melting temperature of the composite metal compound.

The general analysis of compounds, suitable for use as the top (Layer 1) of the NMCC (i.e., less prone to thermal activation) reveals that, from the concept of thermodynamics, the preference should be given to carbides and nitrides of refractory metals of Group IV and partly Groups V and VI of the periodic table as well as oxides and nitrides of aluminum $(\mathrm{Al})$.

The analysis of the dependencies (1-5) reveals that, in choosing the material for the wear-resistant layer of multilayered composite coating with the assumption made about the prevailing influence of adhesion-fatigue processes on the wear of carbide tools, the preference should be given to solid refractory compounds.

To form adhesive Layer 3 of NMCC, the preference was given to compounds with metallic bonds (such as $\mathrm{Ti}$, $\mathrm{Zr}, \mathrm{Cr}, \mathrm{TiN}, \mathrm{CrN}$, etc.). To form intermediate Layer 2 , it is reasonable to use compounds with ionic bonds (such as $\mathrm{SiC}, \mathrm{Si}_{3} \mathrm{~N}_{4}, \mathrm{Al}_{2} \mathrm{O}_{3}, \mathrm{AlN}$, etc.).

It should be noted that, in addition to the determination of the compositions and the mechanical and physical-chemical properties of the basic layers of NMCC and the need to maximize the strength of adhesion between the layers and the carbide substrate, another important parameter of NMCC is its structure, which has a strong influence on the fatigue strength of the NMCC in general.

It is known from [15-18] that ultra-fine materials with an enlarged area of grain boundaries are characterized by high toughness and by their resistance to the emergence and development of "brittle" cracks, as they can more efficiently resist fracture under complex external influences. In this context, the development of coatings for tools should be based on the architecture, characterized by a nano-sized structure, and a multi-layered formation with an increased area of granular and interlayer boundaries, with high resistance to fracture, particularly under conditions of alternating thermomechanical stresses. This concept of coating will allow significantly increasing its lifetime and predicting a significant increase in time between failures for the cutting tool.

The increase of the area of granular and interlayer boundaries may be achieved through formation of a nanocrystalline grain structure and super multi-layered architecture with nanometer thickness of sublayers of each layer of NMCC. This has caused a pronounced relation between the properties of the material and the nature of its macro- and microfractures (elastic, brittle, abrasive, adhesive-fatigue, chemical-oxidative, diffusive, etc.). The intensity of tool wear highly depends on the corresponding relation between the toughness and hardness of the NMCC layers. The granular and interlayer boundaries are an area of intense dissipation of energy and deviation from cracks in the direction of motion and partial or complete inhibition, which results in hardening of the material. On this basis, the use of multi-layered architecture of the NMCC provides an increase in tool life of a 
carbide tool, especially under conditions of cyclic thermomechanical stresses. Moreover, granular boundaries, which contribute to the formation of grain size and the texture of the material, can effectively strengthen coatings $[1,3,4,7,19,20]$.

\section{Experimental details}

\subsection{Deposition method}

For coating deposition, a vacuum-arc VIT-2 unit was used, which was designed for the synthesis of coatings on substrates of various tool materials. The unit is equipped with an arc evaporator with filtration of vapor-ion flow, which was named filtered cathodic vacuum-arc deposition (FCVAD) in this study and was used for deposition of the coatings on the tool, significantly reducing the formation of the droplet phase during the formation of coating. The use of the FCVAD process does not cause structural changes in carbide and provides the following:

- High adhesive strength of the coating in relation to the carbide substrate;

- Control of the level of the "healing" of energy impact on surface defects in carbide in the form of microcracks and micropores and the formation of favorable residual compressive stresses in the surface layers of the carbide material;

- Formation of the nanoscale structure of the deposited coating layers (grain size and sublayer thickness) with high density due to the energy supplied to the deposited condensate and transformation of the kinetic energy of the bombarding ions into thermal energy in the local surface volumes of the carbide material at an extremely high rate of about $10^{14} \mathrm{~K} . \mathrm{s}^{-1}$.

The procedure for preparation of samples of carbide tools with the NMCC for the studies included the following:

- Rewashing the cutting carbide inserts (CI) in chemically activated fluid with the use of ultrasonic vibration;

- Securing the cutting inserts in special devices and placing in a vacuum chamber of the installation VIT-2;

- Creating a vacuum of the order of $p=0.01 \mathrm{~Pa}$ followed by a thin (ionic) cleaning of cutting inserts with gas ions of Ar or metal ions of $\mathrm{Ti}, \mathrm{Zr}$, or $\mathrm{Cr}$ and thermal activation of tool samples with electrons generated from glow discharge;

- Forming NMCC with the appropriate composition and properties on the surfaces of the cutting inserts made of different grades of carbide.

\subsection{Objects of study}

The subject study was represented by coated and uncoated CI made of carbide ( $\mathrm{WC}+15 \% \mathrm{TiC}+6 \% \mathrm{Co})$ of SNUN form (ISO) with nose radius $r_{\varepsilon}=0.8 \mathrm{~mm}$. According to the results, preliminary studies have been selected for the NMCC corresponding the requirements of coatings for carbide tools. The criterion for this selection was the thermodynamic criterion "Gibbs energy $\Delta G$ of the reaction" (Eq. (3)). It was assessed as a two-dimensional space between the interatomic boundary layers "NMCCcarbide" and contacting layers "machined material - the wear resistance layers of NMCC". In the first case, the high adhesion strength during its formation at temperatures of $500-1500{ }^{\circ} \mathrm{C}$ between the adhesive layer and the carbide will be provided at a negative value of $\Delta G$. In the second case, the wear layer NMCC will have a minimal tendency to adhere to the machined material with a positive value of $\Delta G$.

When choosing the composition of the NMCC layers, forming the coating of the three-layered architecture, the Hume-Rothery rule was used (difference in atomic dimensions in contacting compounds should not exceed $20 \%$ ).

For testing, the following series of samples was prepared in the form of replaceable CI with NMCCs of various compositions and architectures:

- TiN (as a "referent" coating for tests),

- Ti-TiN-(TiCrAl)N,

- Zr-ZrN-(ZrCrAl)N,

- Zr-ZrN-(ZrNbCrAl)N,

- Cr-CrN-(TiCrAl)N,

- Ti-TiN-(NbZrTi)N,

- Ti-TiN-(NbZrAl)N,

- Ti-TiN-(NbZrTiAl)N, and

- Cr-CrAlN-(NbZrCrAl)N.

\section{Results and discussion}

\subsection{Coating characterization}

The study presents research on such important characteristics of coatings as adhesion to the substrate, tribological properties, chemical and phase-structural composition, and microstructure on transversal cross-section.

The tests were carried out on a Nanovea scratchtester. The indenter represents a diamond cone with an apex angle of $120^{\circ}$ and radius of the top curvature of $100 \mu \mathrm{m}$. The tests were carried out with a linearly increasing load from $0.05 \mathrm{~N}$ to $40 \mathrm{~N}$. The crack length was $5 \mathrm{~mm}$. Each sample was subjected to three trials. The obtained curves were used to determine two parameters: the first critical load $L_{C 1}$, at which the first cracks appeared in NMCC, and the second critical load $L_{C 2}$, which caused the total failure of the NMCC.

Typical types of failures of NMCC and the standard coating TiN are presented in Figure 2.

Scratching with a diamond indenter with a critical normal load on the indenter causes the failure of the coating along the scratch. Only partial failure is observed in the wedge chipping in the scratched NMCC (Fig. 3). Then, in the scratch on the surface of the coating, the total (continuous) failure of a mono-layered coating along the scratch is observed (Fig. 2b). The typical curves of the changes in loads, the acoustic emission sensor, and 


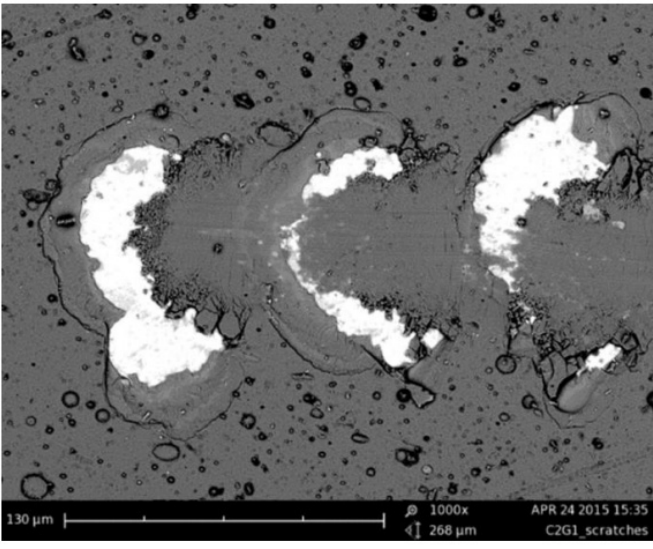

(a)

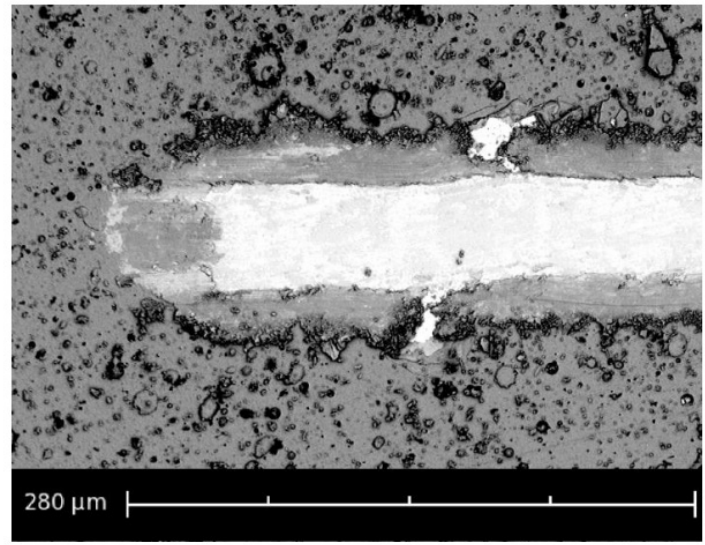

(b)

Fig. 2. The nature of the failure of the NMCC based on Ti-TiN-(TiCrAl)N (a) and coating TiN (b) along a longitudinal crack, caused by a diamond indenter at the critical (breaking) load.

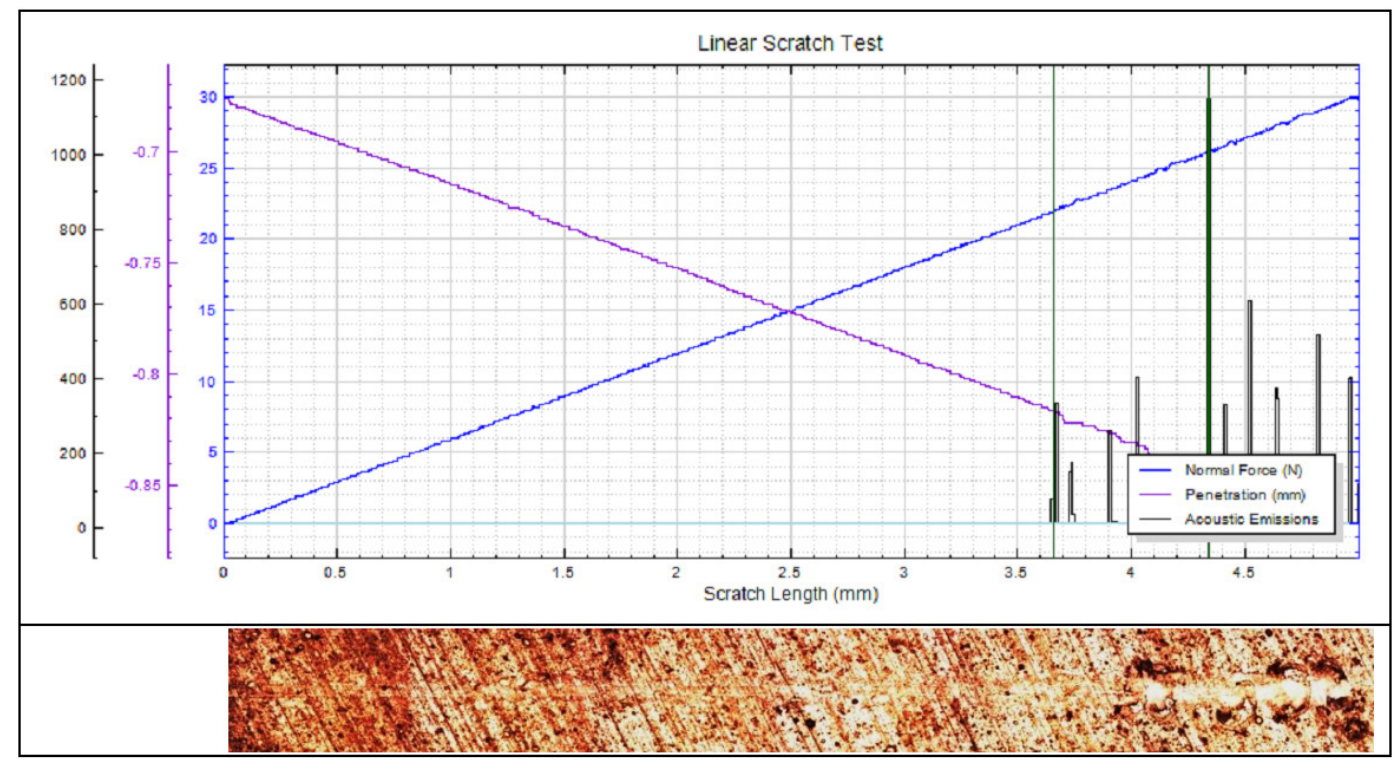

Fig. 3. Curve and panorama of a crack on a sample with the NMCC Ti-TiN-(TiCrAl)N.

the panoramas of scratches on the carbide samples (WC $+15 \% \mathrm{TiC}+6 \% \mathrm{Co})$ with the NMCC are shown in Figures 3-6.

It should be noted that even with the maximum possible load of $40 \mathrm{~N}$ on a diamond indenter at different rates of loads, no failure of the NMCC based on the system Cr-CrN-(TiCrAl)N was observed (Fig. 4).

The application of the maximum possible load of $40 \mathrm{~N}$ also did not result in the complete failure of the NMCC based on the system Ti-TiN-(NbZrTiAl)N (Fig. 5), and only partial failure was observed along the crack. Thus, only the first critical load $L_{C 1}$ was determined.

On a carbide sample of TT10K8-B with the NMCC based on the system Cr-CrAlN-(NbZrCrAl)N (Fig. 6), failure by wedge chipping was observed. No centers of the original failure of the NMCC are observed; thus, only $L_{C 2}$ is determined.
Table 1. Adhesion strength of NMCC on the substrate of carbide TT10K8B.

\begin{tabular}{ccc}
\hline Structure of NMCC & $L_{C 1}$ & $L_{C 2}$ \\
\hline TiN & 20 & 25 \\
Ti-TiN-(TiCrAl)N & 28 & 36 \\
Zr-ZrN-(ZrCrAl)N & 36 & 39 \\
Zr-ZrN-(ZrNbCrAl)N & 34 & 39 \\
Cr-CrN-(TiCrAl)N & 21 & $>40$ \\
Ti-TiN-(NbZrTi)N & 26 & 33 \\
Ti-TiN-(NbZrAl)N & 25 & 31 \\
Ti-TiN-(NbZrTiAl)N & 34 & $>40$ \\
Cr-CrAlN-(NbZrCrAl)N & - & 28 \\
\hline
\end{tabular}

Table 1 presents the results of the experimental data to obtain the values of $L_{C 1}$ and $L_{C 2}$ that characterize the adhesion strength of the NMCC with respect to the carbide substrate. 


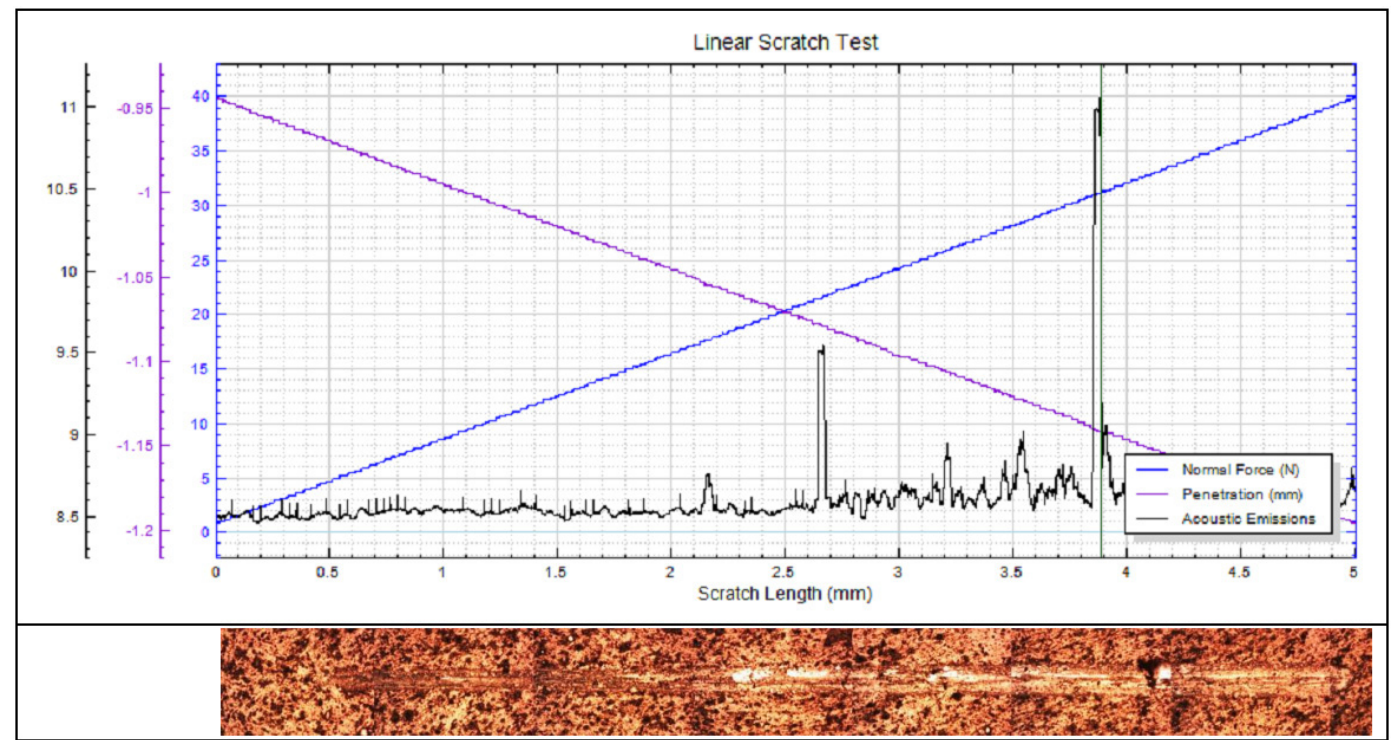

Fig. 4. Curve and panorama of a crack on a sample with NMCC based on Cr-CrN-(TiCrAl)N.

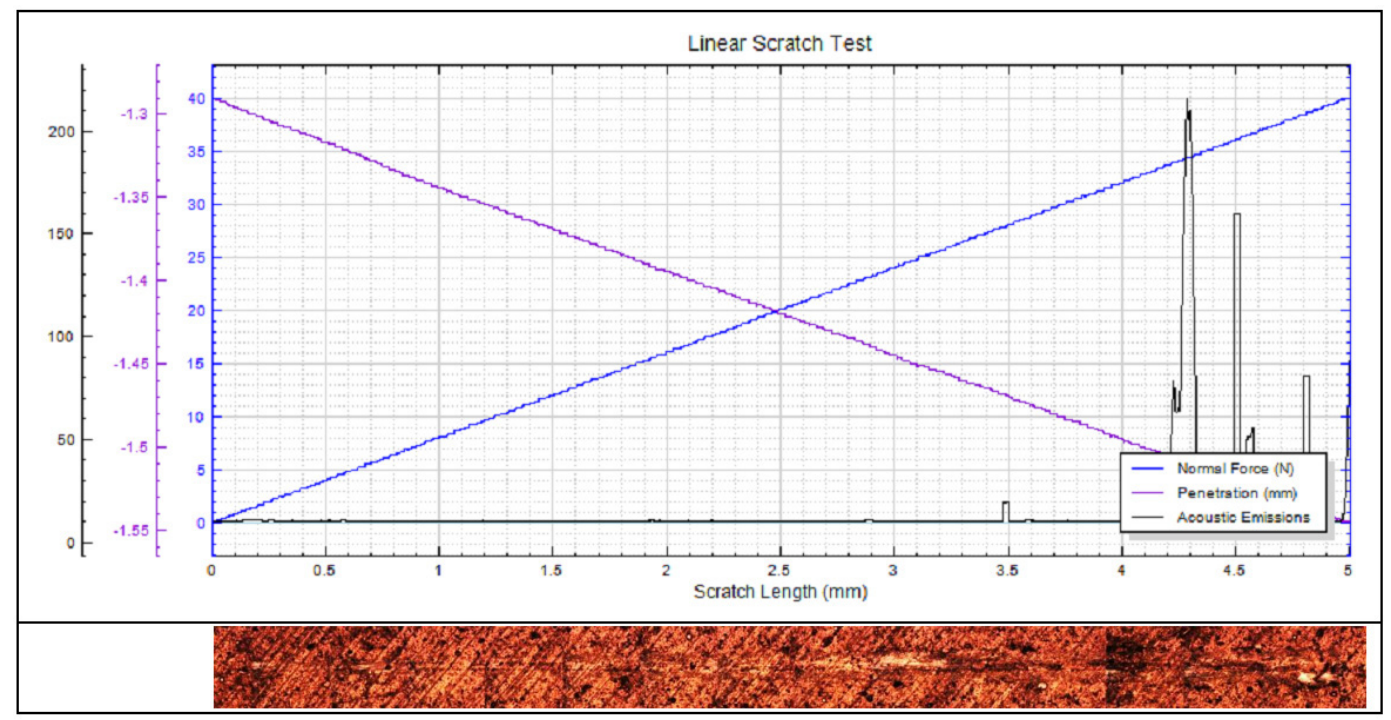

Fig. 5. Curve and panorama of a crack on a sample with the NMCC Ti-TiN-(NbZrTiAl)N.

The study revealed a high adhesion strength of the tested NMCC. It was found that the most common type of NMCC failure was wedge chipping.

\subsection{Studies of NMCC microstructure}

For microstructural investigations, the study used a raster electron microscope FEI Quanta 600 FEG. The objectives of the microstructural investigations were as follows:

- Accurate determination of the total thickness of the NMCC and the thickness of each sublayer (adhesive, intermediate, and wear-resistant);

- Study of the nanostructure of the sublayers of the NMCC and determination of the thickness of the nano-layers;
- Detection of the possible internal defects of the NMCC (micropores, pure metal particles, microdroplets, internal cracks, etc.).

The research of the microstructure of the NMCC on the transverse cross-section has resulted in the following conclusions:

- The total thickness of the NMCC is 2.8-3.1 $\mu \mathrm{m}$;

- The thickness of the wear-resistant layer is $0.8-1.1 \mu \mathrm{m}$;

- The thickness of the intermediate layer is $0.9-1.5 \mu \mathrm{m}$;

- The thickness of the adhesive layer is $0.5-0.8 \mu \mathrm{m}$;

- In some cases, there are additional transition layers with thickness of $0.2-0.5 \mu \mathrm{m}$ between the wearresistant layer and the intermediate layer. These layers are formed due to the need for an additional heating of system "coating-substrate" during bombardment with metal ions prior to deposition of the wear-resistant 


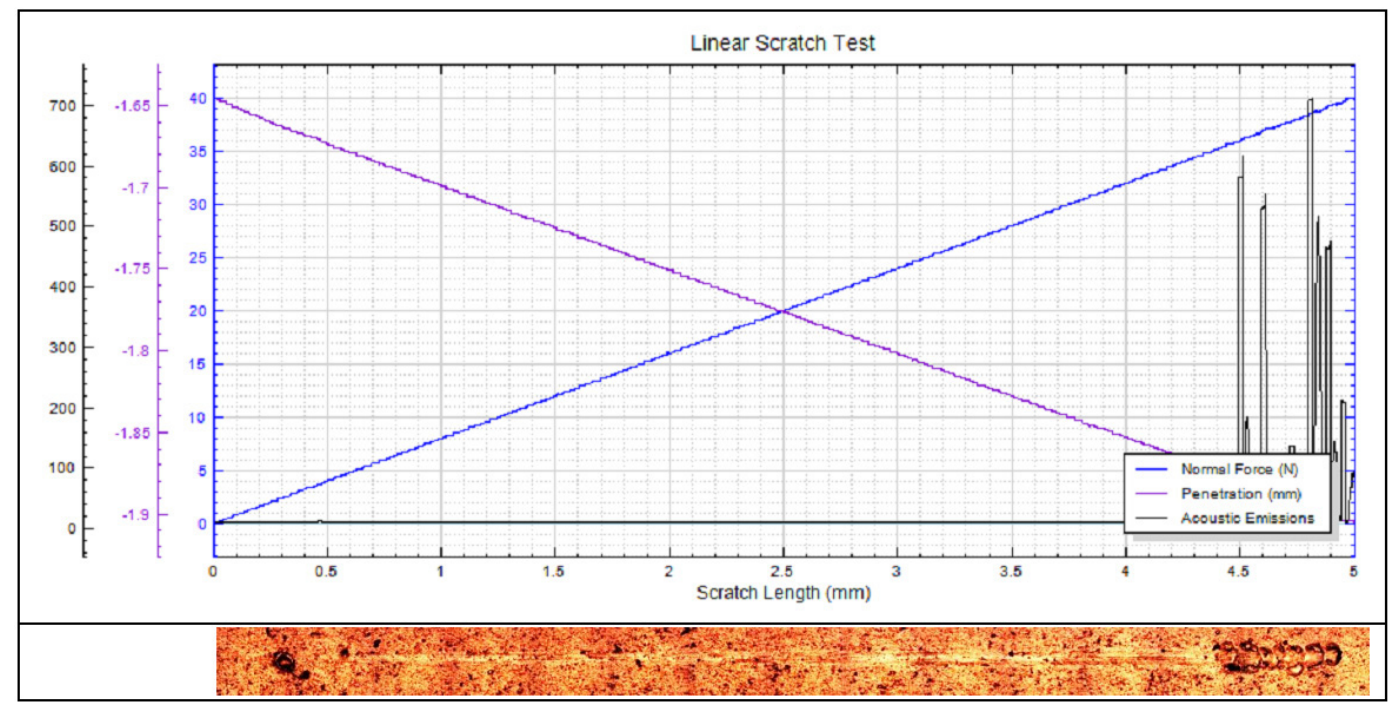

Fig. 6. Curve and panorama of a crack on a sample with the NMCC Cr-CrAlN-(NbZrCrAl)N.

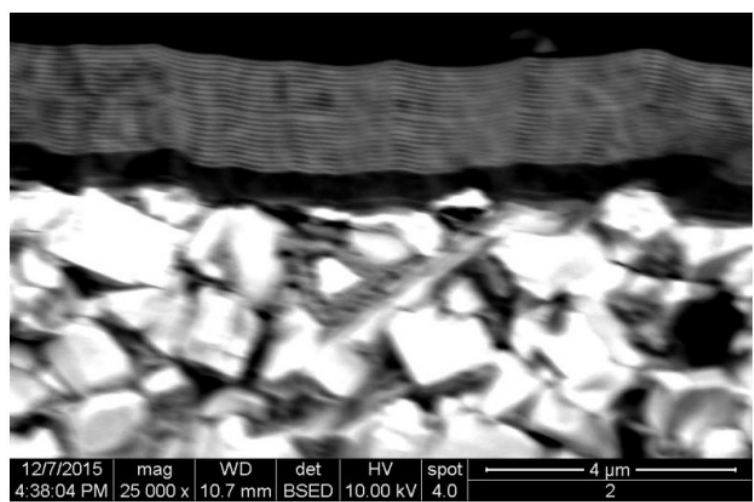

(a)

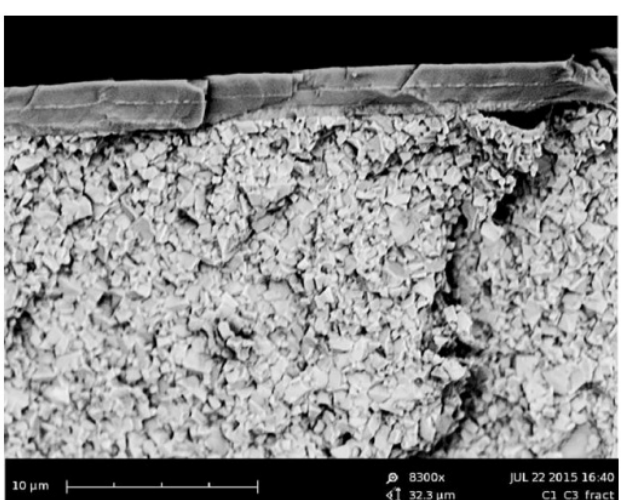

(b)

Fig. 7. The microstructure of the fracture of the NMCC based on the systems Ti-TiN-(NbZrTiAl)N (a) and the Zr-ZrN( $\mathrm{ZrCrAl}) \mathrm{N}(\mathrm{b})$ on the carbide substrate.

layer. In some cases, the same layer is also formed between the adhesive layer and the intermediate layer;

- The thickness of the nano-layers of the wear-resistant layer and the intermediate layer reaches $50-150 \mathrm{~nm}$;

- The adhesive sublayer has no distinct nanostructure, except for the adhesive layer shown in Figure 10, with nano-layers of about $50 \mathrm{~nm}$.

Further tests have revealed that the NMCCs with lower nano-layers are generally characterized by a higher wear resistance. The most important results of the microstructural investigations of the samples made of carbide are presented in Figures 8-10.

Figures $7 \mathrm{a}$ and $7 \mathrm{~b}$ show the microstructure of the fracture of the sample with the coating Ti-TiN-(NbZrTiAl)N (a) and $\mathrm{Zr}-\mathrm{ZrN}-(\mathrm{ZrCrAl}) \mathrm{N}$ (b) on the substrate of the carbide. The sublayer immediately adjacent to the substrate has a different structure from the structures of the other sublayers. There is a case of "inheritance" of the grain structure of the substrate, which may result from the diffusion of the first sublayer material into the substrate material.

\subsection{Cutting property studies}

The studies on the cutting properties of the carbide tool with the developed NMCC were conducted on a lathe CU 500 MRD in longitudinal turning of steel C45 (HB 200). The study used cutters with mechanical fastening of square CI (SNUN ISO 1832:2012) and with the following figures of the geometric parameters of the cutting part: $\gamma=-8^{\circ}, \alpha=6^{\circ}, k=45^{\circ}, \lambda=0$, and $r=0.8 \mathrm{~mm}$. Moreover, the study was carried out at the following cutting modes: $f=0.2 \mathrm{~mm} \cdot \mathrm{rev}^{-1}, a_{p}=1.0 \mathrm{~mm}$, and $v=200-350 \mathrm{~m} \cdot \mathrm{min}^{-1}$.

Flank wear land $V B_{c}=0.45-0.5 \mathrm{~mm}$ was taken as a failure criteria. It was measured with a toolmaker's microscope MBS-10 as the arithmetic mean of four to five tests. The results were processed using parametric identification using an exponential stochastic multiplicative 


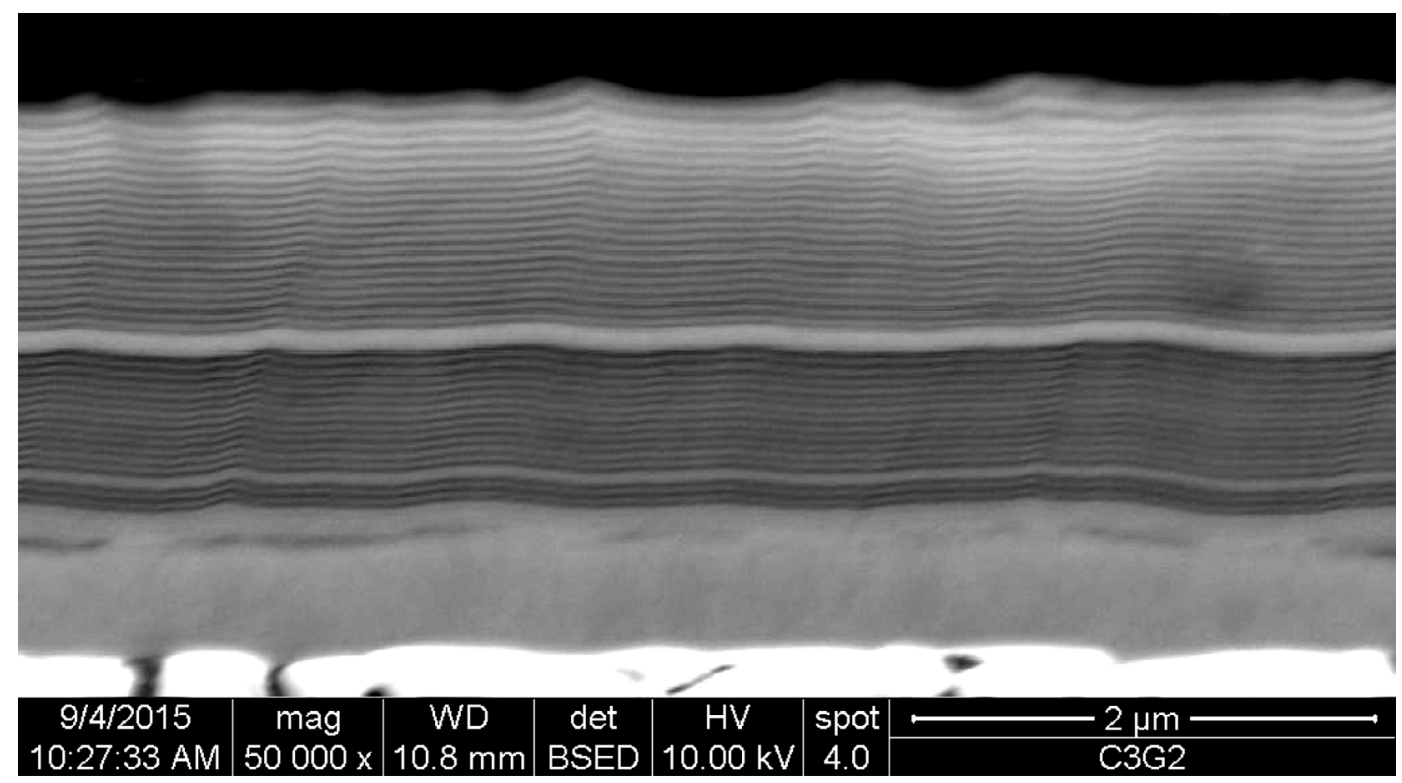

Fig. 8. The microstructure of the NMCC $\mathrm{Zr}-\mathrm{ZrN}-(\mathrm{ZrCrAl}) \mathrm{N}$ on the transversal cross-section. The thickness of the nano-layers is $15-45 \mathrm{~nm}$; the coating thickness is $2.44 \mu \mathrm{m}$.

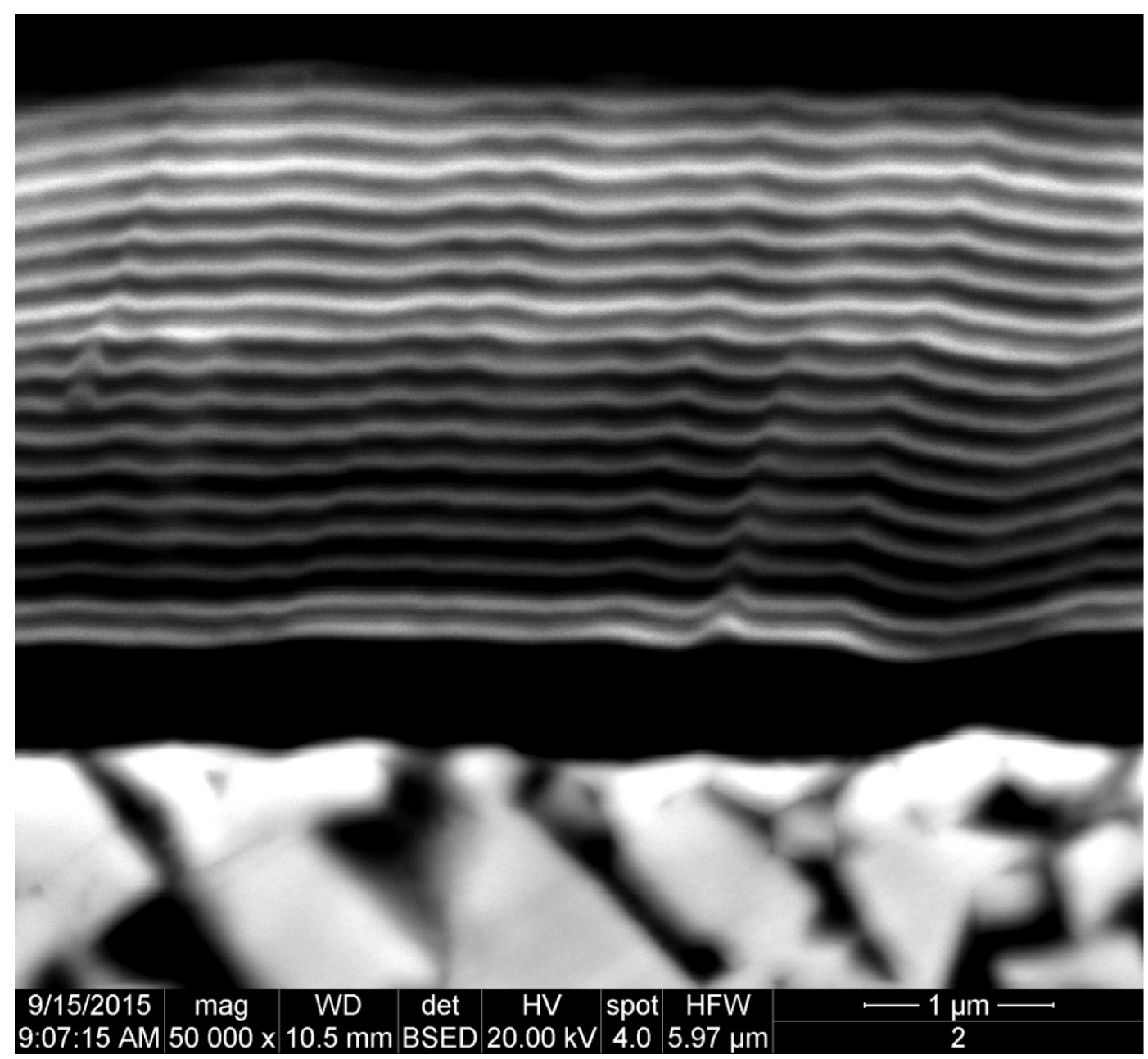

Fig. 9. The microstructure of the NMCC Ti-TiN-(NbZrTi)N on the transversal cross-section. The thickness of the nano-layers is $55-75 \mathrm{~nm}$; the coating thickness is $3.55 \mu \mathrm{m}$. 


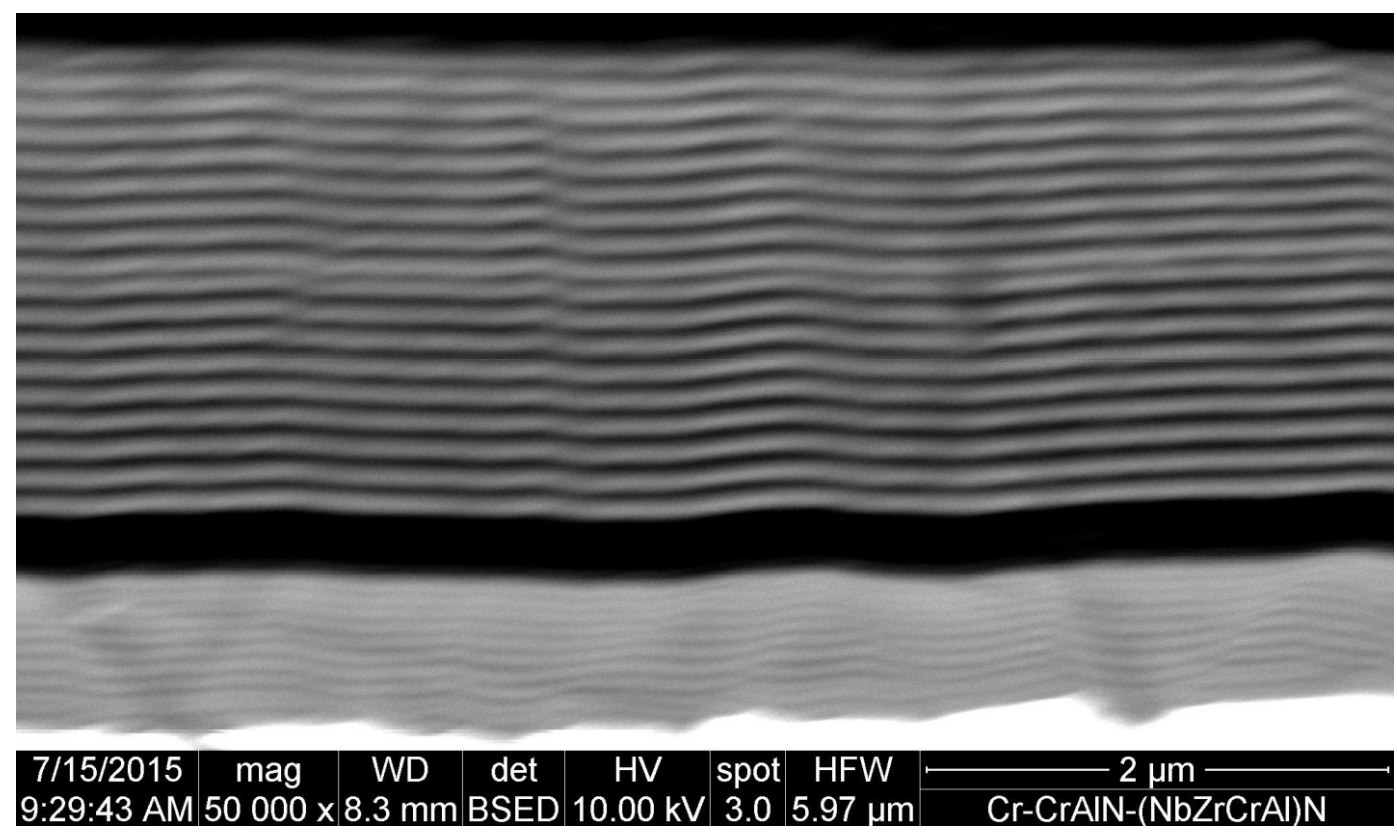

Fig. 10. The microstructure of the NMCC Ti-TiN-(NbZrTiAl)N on the transversal cross-section. The thickness of the nanolayers is $45-75 \mathrm{~nm}$; the coating thickness is $2.92 \mu \mathrm{m}$.

mathematical model by the least squares method of the form:

$$
V B=C(1) v_{c}^{A(1,1)} T^{A(1,2)}
$$

The curves obtained by the mathematical processing of the experimental data are shown in Figures 11-14.

A summary of the evaluation of cutting properties of carbide tools, depending on the processing conditions and mechanical properties, are presented in Table 2.

The analysis of the obtained data reveals the following:

- The carbide tools with a NMCC of a thickness of 2.35$2.75 \mu \mathrm{m}$ and a thickness of nano-layers of $15-45 \mathrm{~nm}$ showed longer tool life than the tools with the NMCC with a thickness of $2.92-3.55 \mu \mathrm{m}$ and a thickness of nano-layers of $45-75 \mathrm{~nm}$;

- The carbide tools with the NMCC with the threelayered architecture, with adhesive and intermediate layers based on $\mathrm{Zr}-\mathrm{ZrN}$ and $\mathrm{Ti}-\mathrm{TiN}$, showed longer tool life than the tools with the NMCC based on the system $\mathrm{Cr}-\mathrm{CrN}$;

- No direct correlation is detected between the value of $L_{C 2}$, characterizing the adhesion strength between the NMCC and the substrate, and the tool life of carbide tools with the NMCC; meanwhile, the NMCC with low values of $L_{C 2}$ (31 and lower) showed the shortest tool life.

\section{Conclusion}

The research facilitated developing the methodology for the formation of the architecture, phase, and elemental composition, structure, and properties of the NMCC designed for deposition on carbide substrates. The methodology and requirements for the coatings based on it were developed with the phenomenological theory of the thermodynamic criteria for the evaluation of the adhesion of the system "carbide-coating," and the assumption of the prevailing mechanism of adhesion-fatigue wear of carbide tools in cutting.

The synthesis of coatings was carried out through FCVAD. The FCVAD process not only improves the quality of the NMCC due to the almost complete (up to 90-95\%) filtration of macro- and micro-droplet components of the vapor-ion flow, but it also avoids electro-erosion etching of the cutting edges and working surfaces of the tool, contributing to the formation of nanoscale grain structure and thickness of sublayers of the NMCC of the threelayered architecture.

The architecture, composition, and structure of the NMCC were determined in accordance with the developed methodological requirements for deposition on the carbide substrates and were developed based on the nitrides of refractory metals of the IV-VI groups of the periodic table and Al. The detailed investigations were focused on the NMCC based on the systems Ti-TiN-(TiCrAl)N, $\mathrm{Zr}-\mathrm{ZrN}-(\mathrm{ZrCrAl}) \mathrm{N}, \quad \mathrm{Zr}-\mathrm{ZrN}-(\mathrm{ZrNbCrAl}) \mathrm{N}, \quad \mathrm{Cr}-\mathrm{CrN}-$ (TiCrAl)N, Ti-TiN-(NbZrTi)N, Ti-TiN-(NbZrAl)N, Ti-TiN-(NbZrTiAl)N, and Cr-CrAlN-(NbZrCrAl)N.

The results of the investigations of the elemental and phase composition of the NMCC based on the threelayered architecture as well as the tribological and adhesive properties revealed the following:

- The total thickness of the NMCC reached 2.8-3.1 $\mu \mathrm{m}$;

- The thickness of the wear-resistant layer of the NMCC reached $0.8-1.1 \mu \mathrm{m}$; 
S.N. Grigoriev and A.A. Vereshchaka: Mechanics \& Industry 17, 706 (2016)

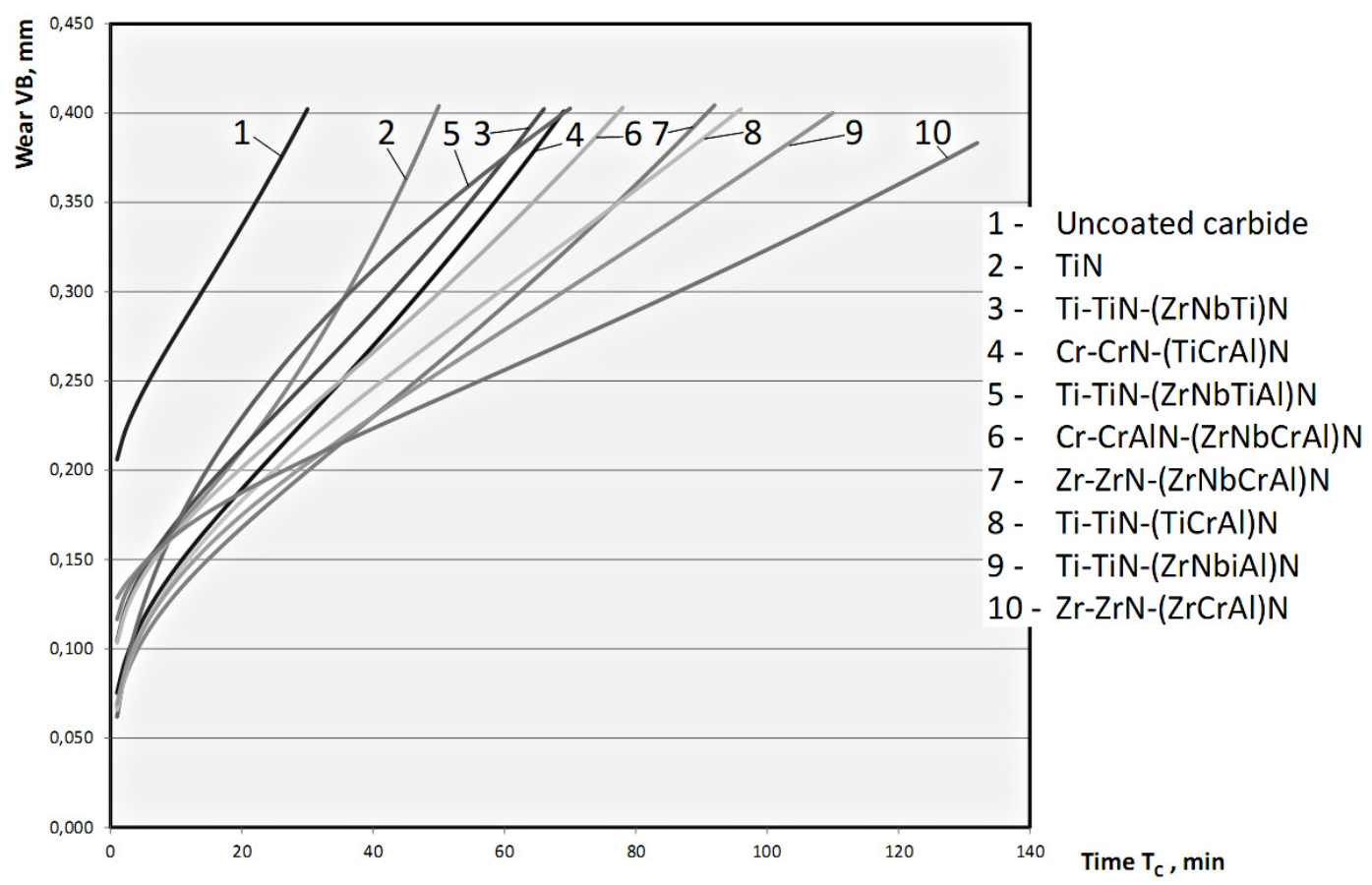

Fig. 11. Dependence of wear $V B$ on the cutting time at dry turning of steel $\mathrm{C} 45$ at $a_{p}=1.0 \mathrm{~mm}, f=0.2 \mathrm{~mm} . \mathrm{rev}^{-1}$, and $v_{c}=200 \mathrm{~m} \cdot \mathrm{min}^{-1}$.

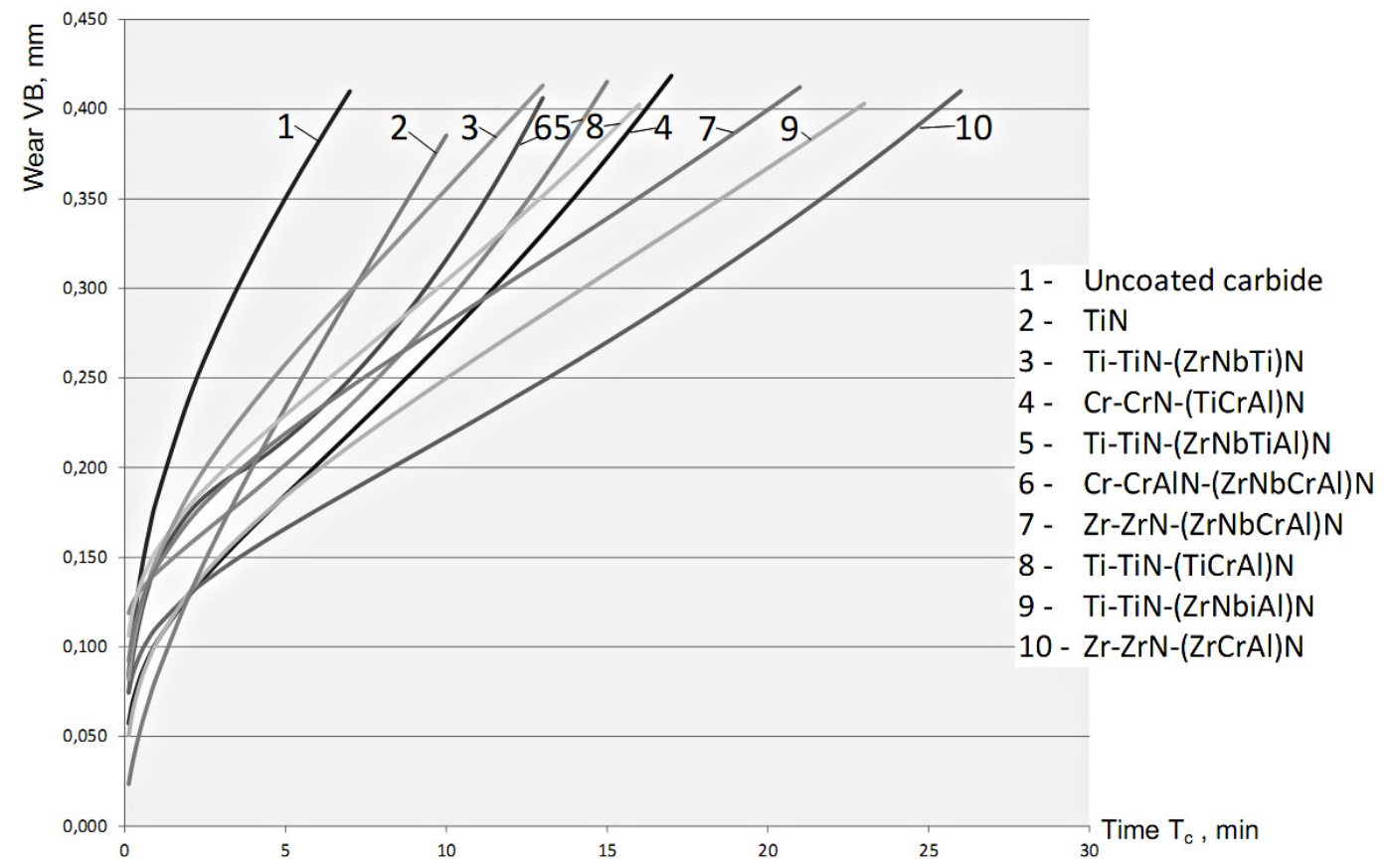

Fig. 12. Dependence of wear $V B$ on the cutting time at dry turning of steel C45 at $a_{p}=1.0 \mathrm{~mm}, f=0.2 \mathrm{~mm} . \mathrm{rev}^{-1}$, and $v_{c}=250 \mathrm{~m} \cdot \mathrm{min}^{-1}$. 
S.N. Grigoriev and A.A. Vereshchaka: Mechanics \& Industry 17, 706 (2016)

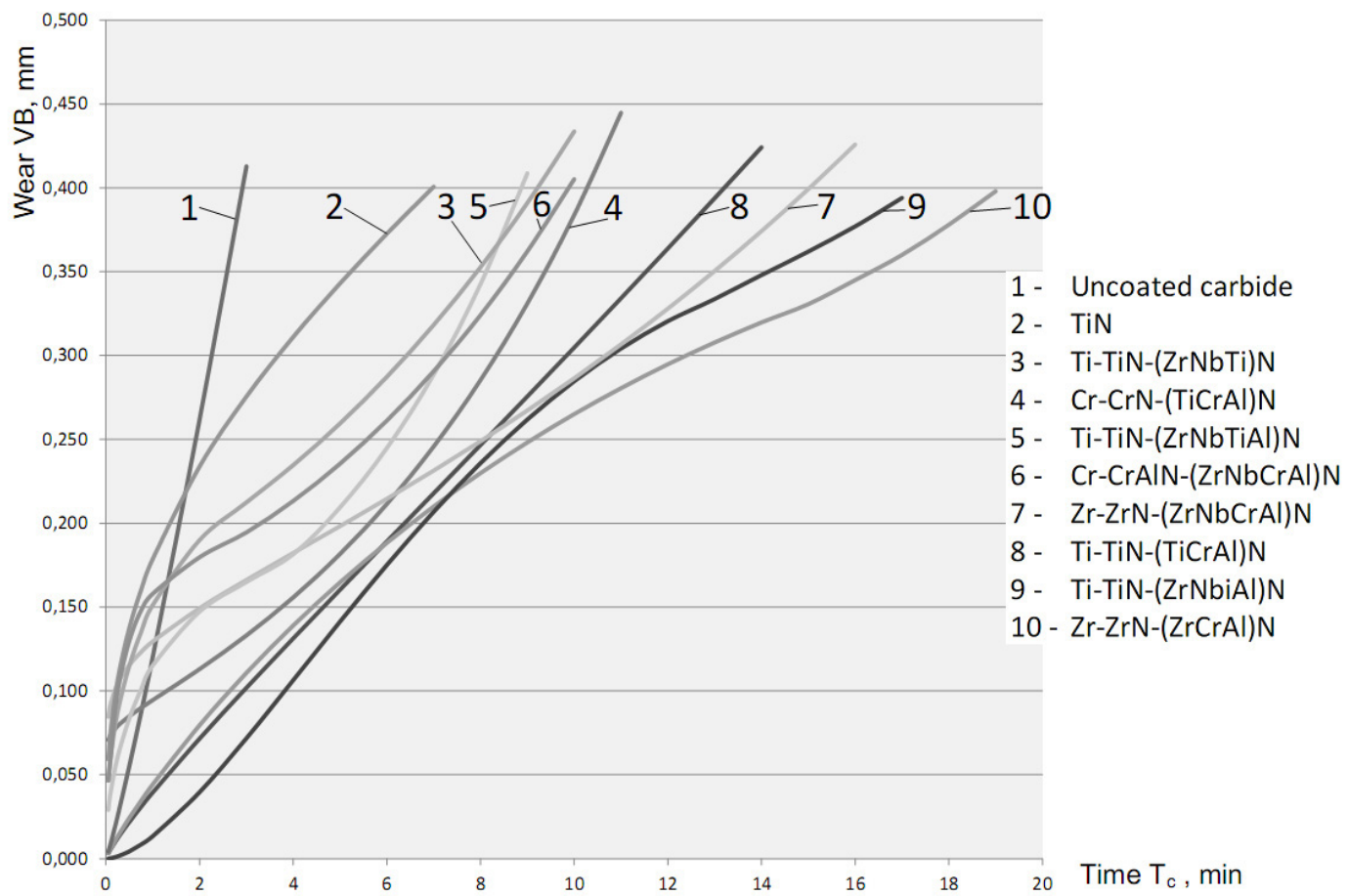

Fig. 13. Dependence of wear $V B$ on the cutting time at dry turning of steel C45 at $a_{p}=1.0 \mathrm{~mm}, f=0.2 \mathrm{~mm}^{\mathrm{r} e \mathrm{v}^{-1}}$, and $v_{c}=300 \mathrm{~m} \cdot \mathrm{min}^{-1}$.

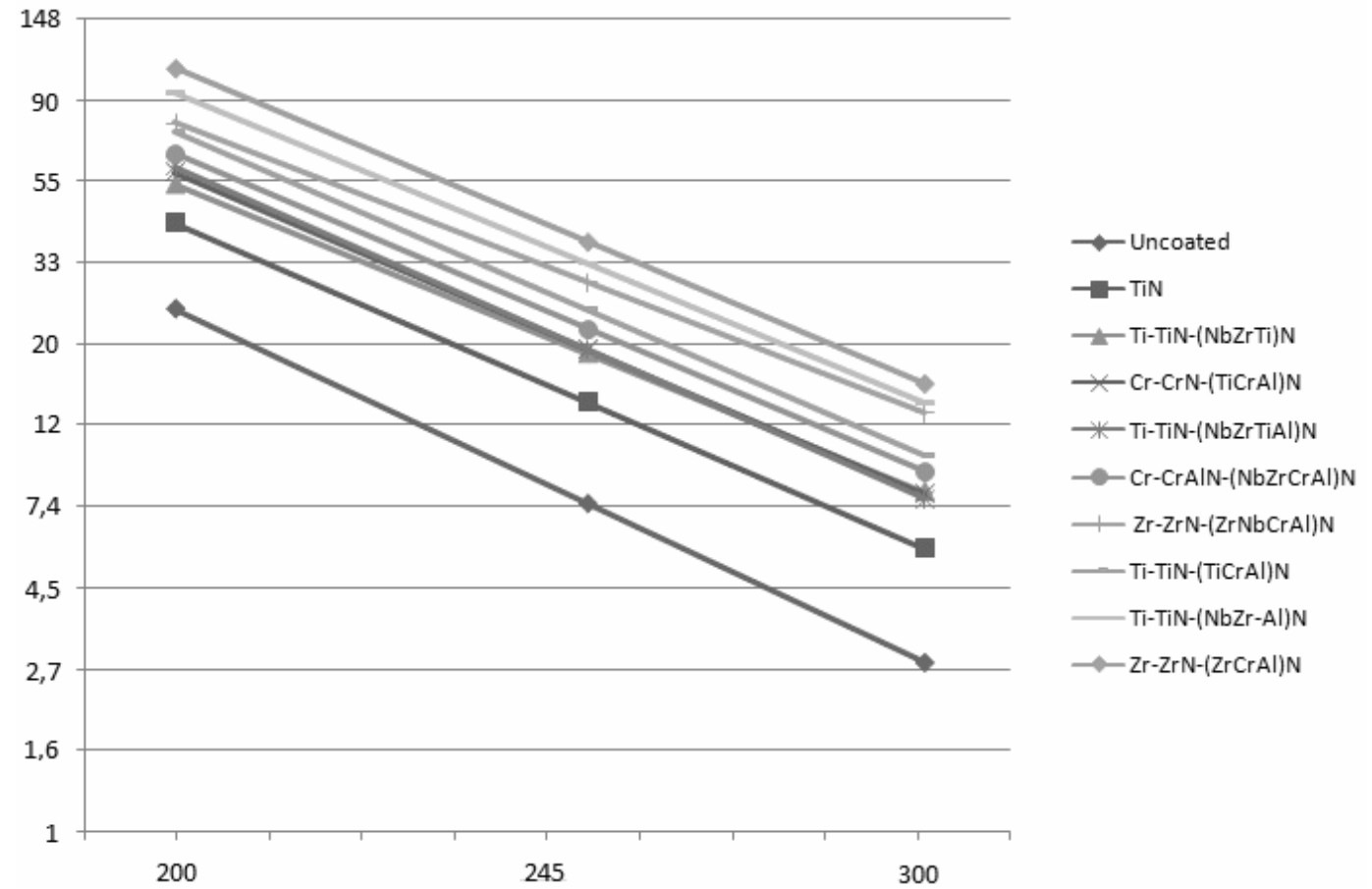

Fig. 14. Effect of the cutting speed on tool life $T$ for longitudinal turning steel C45 with $f=0.2 \mathrm{~mm} \cdot \mathrm{rev}^{-1} \mathrm{and} a_{p}=1.0 \mathrm{~mm}$. 
S.N. Grigoriev and A.A. Vereshchaka: Mechanics \& Industry 17, 706 (2016)

Table 2. Dependence of tool life for tools made of carbide with NMCC on cutting speed $v_{c}$.

\begin{tabular}{|c|c|c|c|c|c|c|c|c|}
\hline \multirow[t]{2}{*}{$\#$} & \multirow[t]{2}{*}{ Structure of NMCC } & \multicolumn{3}{|c|}{$\begin{array}{l}\text { Tool life }(\mathrm{min}), \text { depending } \\
\text { cutting speed }\left(\mathrm{m} \cdot \mathrm{min}^{-1}\right)\end{array}$} & \multicolumn{2}{|c|}{$\begin{array}{l}\text { Coating Sub layer }(\mathrm{nm}) \\
\text { and Total Thickness }(\mu \mathrm{m})\end{array}$} & \multirow[t]{2}{*}{$\begin{array}{c}\text { Adhesion } \\
L_{C 2}, \mathrm{~N} \\
\end{array}$} & \multirow[t]{2}{*}{$\begin{array}{c}\text { Hardness }^{m *} \\
\text { HV GPa }\end{array}$} \\
\hline & & $v_{c}=200$ & $v_{c}=250$ & $v_{c}=300$ & $\mathrm{~nm}$ & $\mu \mathrm{m}$ & & \\
\hline 1 & Zr-ZrN-(ZrCrAl)N & 129 & 27 & 19 & $15-45$ & 2.44 & 39 & 38 \\
\hline 2 & Ti-TiN-(NbZr-Al)N & 110 & 23 & 17 & $30-45$ & 2.35 & 33 & 39 \\
\hline 3 & $\mathrm{Zr}-\mathrm{ZrN}-(\mathrm{ZrNbCrAl}) \mathrm{N}$ & 93 & 21 & 16 & $45-75$ & 3.05 & 39 & 42 \\
\hline 4 & Ti-TiN-(TiCrAl)N & 91 & 16 & 13 & $20-40$ & 2.56 & 36 & 40 \\
\hline 5 & $\mathrm{Cr}-\mathrm{CrN}-(\mathrm{TiCrAl}) \mathrm{N}$ & 79 & 15 & 11 & $30-45$ & 2.75 & $>40$ & 41 \\
\hline 6 & Ti-TiN-(NbZrTiAl)N & 69 & 17 & 9 & $45-60$ & 3.30 & $>40$ & 36 \\
\hline 7 & Cr-CrAlN-(NbZrCrAl)N & 69 & 13 & 10 & $45-75$ & 2.92 & 28 & 38 \\
\hline 8 & Ti-TiN-(NbZrTi)N & 64 & 13 & 10 & $55-76$ & 3.55 & 31 & 34 \\
\hline 9 & $\mathrm{TiN}$ & 50 & 10 & 7 & - & 2.85 & 25 & 30 \\
\hline 10 & Uncoated carbide & 26 & 7 & 3 & - & - & - & 28 \\
\hline
\end{tabular}

*Hardness (HV) of coatings was determined by measuring the indentation at low loads, per the method of Oliver and Pharr, on a micro-indentometer Micro-Hardness Tester (CSM Instruments) at a fixed load of $300 \mathrm{mN}$. The penetration depth of the indenter was monitored so that it did not exceed $10-20 \%$ of the coating thickness to limit the influence of the substrate.

- The thickness of the intermediate layer of the NMCC reached $0.9-1.5 \mu \mathrm{m}$;

- The NMCC had a nanoscale grain structure of 15$20 \mathrm{~nm}$, and the thickness of the sublayers of the wearresistant and intermediate layers reached $15-45 \mathrm{~nm}$;

- In some cases, the transition layers with thicknesses of $0.2-0.51 \mu \mathrm{m}$ were detected between the wear-resistant layer and the intermediate layer of the NMCC, which were formed due to the auxiliary heating of the system "coating-substrate" during bombardment with metal ions before deposition of the wear-resistant layer. In some cases, a similar layer was formed between the adhesive layer and intermediate layer;

- It was revealed that, in general, the adhesive underlayer of the NMCC had no distinct layered nanostructure, although many cases showed a layered nanostructure of the adhesive underlayer with the thickness of the sublayer of $50 \mathrm{~nm}$ (Fig. 10).

These results allow the classification of the synthesized NMCC as nanostructured with the increased area of intergranular and interlayer boundaries that provide a considerably balanced relation of the most important characteristics of the coating, such as "hardness-toughness". Such nanoscale structures of coatings are characterized by increased toughness and resistance to the formation and development of "brittle" cracks and more efficient resistance to fractures in conditions of complex stress from external influences in comparison with coatings of similar compositions but with micro-dimensional structures.

The analysis of a line diagram of the phases combined with the diffraction spectra reveals the following:

- No direct correlation is revealed between the value $L_{C 2}$, which characterizes the adhesion strength between the NMCC and the substrate, and the tool life of carbide tools with the NMCC, while the NMCC with low values of $L_{C 2}$ (31 and lower) had the lowest wear resistance.
The study of cutting properties of carbide tools with the developed NMCC found the following:

- Carbide tools with the NMCC with thickness of 2.35$2.75 \mu \mathrm{m}$ and thickness of sublayers of about $15-35 \mathrm{~nm}$ showed longer tool life than tools with the NMCC of similar composition, but with thickness of 2.92$3.55 \mu \mathrm{m}$ and thickness of the sublayers of $45-75 \mathrm{~nm}$;

- Carbide tools with the NMCC with three-layered architecture, comprising adhesive and intermediate layers based on $\mathrm{Zr}-\mathrm{ZrN}$ and $\mathrm{Ti}-\mathrm{TiN}$, showed the longest tool life in comparison with the tools with the NMCC based on the system $\mathrm{Cr}-\mathrm{CrN}$.

It is found that, in longitudinal turning of steel, carbide tools with the developed NMCC demonstrated a tool life of up to five times higher than the tool life of the uncoated carbide tools and up to three times higher than that of tools with standard coatings.

Acknowledgements. The work was performed with the financial support of the Russian Science Foundation within the Agreement No.14-29-00297 on August 6, 2014.

\section{References}

[1] K.D. Bouzakis, N. Michailidis, G. Skordaris, E. Bouzakis, D. Biermann, R. M'Saoubi, Cutting with coated tools: Coating technologies, characterization methods and performance optimization, CIRP Annals - Manuf. Technol. 61 (2012) 703-723

[2] G.S. Fox-Rabinovich, B.D. Beake, K. Yamamoto, M.H. Aguirre, S.C. Veldhuis, G. Dosbaeva, A. Elfizy, A. Biksa, L. S. Shuster, Structure, properties and wear performance of nano-multilayered TiAlCrSiYN/TiAlCrN coatings during machining of Ni-based aerospace superalloys, Surf. Coatings Technol. 204 (2010) 3698-3706 
[3] A.A. Vereshchaka, A.S. Vereshchaka, O. Mgaloblishvili, M.N. Morgan, A.D. Batako, Nano-scale multilayeredcomposite coatings for the cutting tools, Int. J. Adv. Manuf. Technol. 72 (2014) 303-317

[4] A. Vereschaka, Development of assisted filtered cathodic vacuum arc deposition of nano-dispersed multi-layered composite coatings on cutting tools, Key Eng. Mater. 581 (2014) 62-67

[5] N.M. Mali, T. Mahender, Wear analysis of single point cutting tool with and without coating, Int. J. Res. Eng. Adv. Technol. 3 (2015) 49-57

[6] A.S. Vereschaka, Working capacity of the cutting tool with wear-resistant coatings Moscow, Mashinostroenie 1993 (In Russian)

[7] M.G. Faga, G. Gautier, R. Calzavarini, M. Perucca, E. Aimo Boot, F. Cartasegna, L. Settineri, AlSiTiN nanocomposite coatings developed via Arc Cathodic PVD: Evaluation of wear resistance via tribological analysis and high speed machining operations, Wear 263 (2007) 1306-1314

[8] E. Moll, E. Bergmann, Hard coatings by plasma-assisted PVD technologies: industrial practice, Surf. Coating Technol. 37 (1989) 483-509

[9] H. Holleck, Basic principles of specific application of ceramic materials as protective layers, Surf. coatings Technol. 43/44 (1990) 245-258

[10] A.A. Vereschakaa, S.N. Grigorieva, A.S. Vereschakaa, A.Y. Popov, A.D. Batako, Nano-scale multilayered composite coatings for cutting tools operating under heavy cutting conditions, Procedia CIRP 14 (2014) 239-244

[11] S. Pal Dey, S.C. Deevi, Single layer and multilayer wear resistant coatings of $(\mathrm{Ti}, \mathrm{Al}) \mathrm{N}$ : a review, Mater. Sci. Eng. A 342 (2003) 58-79

[12] C.-Y. Lay, K.-H. Cheng, S.-J. Lin, J.-W. Yeh, Mechanical and tribological properties of multi-element (AlCrTaTiZr)N coatings, Surf. Coating Technol. 202 (2008) 3732-3738
[13] H. Holleck, V. Schier, Multilayer PVD coatings for wear protection, Surf. Coating Technol. 76-77 (1995) 328-336

[14] K.-D. Bouzakis, N. Michailidis, G. Skordaris, S. Kombogiannis, S. Hadjiyiannis, K. Efstathiou, E. Pavlidou, G. Erkens, S. Rambadt, I. Wirth, Optimisation of the cutting-edge roundness and its manufacturing procedures of cemented carbide inserts, to improve their milling performance after a PVD coating deposition, Surf. Coating Technol. 163-164 (2003) 625-630

[15] A.O. Volkhonskii, A.A. Vereshchaka, I.V. Blinkov, A.S Vereshchaka, A.D Batako, Filtered cathodic vacuum Arc deposition of nano-layered composite coatings for machining hard-to-cut materials, Int. J. Adv. Manuf. Technol. 84 (2016) 1647-1660

[16] T. Cselle, Nanostracturierte Schichten in der Werkstaff, Platit AG. Warkzeugtagung, 2002 (In German)

[17] P.J. Martin, O. Knotek, A. Scherey, et al. Handbook of Film Process Technology, London, IOP Publishing, 1995, p. 218

[18] H. Holleck, Nanoskalige Schutyschichten fur hochbeanspruchte Bauteile, H. Holeck, H. Leiste, A. Ulrich. NACHRICHEN - Forschungszentrum Karlsruhe Jahrg. Vol. 31, 1/99 (1999) pp. 13-20 (In German)

[19] A.À. Vereschaka, M.A. Volosova, A.D. Batako, A.S. Vereshchaka, B.Y. Mokritskii, Development of wearresistant coatings compounds for high-speed steel tool using a combined cathodic vacuum arc deposition, Int. J. Adv. Manuf. Technol. 84 (2016) 1471-1482

[20] A.A. Vereschaka, A.S. Vereschaka, J.I. Bublikov, A.Y. Aksenenko, N.N. Sitnikov, Study of properties of nanostructured multilayer composite coatings of Ti-TiN(TiCrAl)N and $\mathrm{Zr}-\mathrm{ZrN}-(\mathrm{ZrNbCrAl}) \mathrm{N}$, J. Nano Res. 40 (2016) 90-98 